\title{
SURVEY OF KNOWLEDGE AND ATTITUDES ON PREVENTION OF CERVICAL CANCER
}

\author{
Assoc. prof. Galina Terzieva, $\mathbf{P h D}$, assist \\ Prof. d-r Assen Zlatarov University - Burgas, Republic of Bulgaria \\ galina.terzieva@abv.bg \\ Monika Obrejkova- asisstan \\ Prof. d-r Assen Zlatarov University - Burgas, Republic of Bulgaria \\ monika obrejkova@abv.bg
}

Original Scientific Paper doi:10.5937/jouproman4-12017

\begin{abstract}
Cancer of the cervix is the second most common cause of death among women of malignancies after breast cancer. Human Papilloma Virus (HPV) is transmitted through sexual contact (vaginal, anal and oral) and in contact skin-skin in the genital area. It is highly resistant to environmental conditions and is therefore widespread. Every sexually active woman is at risk. HPV is transmitted from man to woman and in most cases the infection is asymptomatic from 6 to 15 years after the time of infection, which further contributes to the spread of the virus. The aim of the research is exploring the opinion of students and their parents about the use of a vaccine to prevent cervical cancer. The subject of the research is the process of building a culture of health of young people and their subject position for participation in health prevention. Objects of the survey are the attitudes, knowledges and assessment of different social groups for protection and preservation of their health and the health of others. Scope of the research are 141 respondents: students and their parents. Approaches and methods for the study of the problem: theoretical analysis of the problem in the medical literature; documentary research; anonymous questionnaire survey; comparative analysis. Results of the study outline the unwillingness of the majority of parents - 54\% to vaccinate their daughters. $62.3 \%$ of students said they "would not be vaccinated because the vaccine is considered as dangerous to health, and because there are not enough studies about the benefits of it."
\end{abstract}

Key words: cancer, cervix, student, HPV (Human Papilloma Virus)

\section{INTRODUCTION}

Cancer of the cervix is an actual and significant problem for health protecting and pedagogical practice [1], [2], [3], [4], [5], [6], [7], [8]. The necessity of prevention of this malignancy is determined by high death-rate, which it causes among women worldwide, as well as in Bulgaria. Cancer of cervix is the second most common cause of death among women of malignancies after breast cancer. About 300 000 women die from this disease every year, and 1400000 women in the world are ill at this moment. Facts from Bulgarian Health Register point that in our country 1000 women get ill annually and 400 of them die. These figures are increasing constantly and concern much younger women. Human Papilloma Virus (HPV) is transmitted from a man to a woman through sexual contact (vaginal, anal and oral) and in contact skin-skin in the genital area. It is highly resistant to environmental conditions and is therefore widespread. Every sexually active woman is at risk. In most cases the infection is asymptomatic from 6 to 15 years after the time of infection, which further contributes to the spread of the virus. Vaccines are offered on Bulgarian market which are claimed to be very effective (98\% for one of them and $92 \%$ for the other). The applied vaccines aren't pointed towards cancer as a whole, but towards the virus that causes the cancer. They lessen the risk of getting ill, but do not eliminate it at all, because they protect the organism only from the types, which are aimed to. 
They do not have cure effect, do not treat the infection, do not destroy the viruses. The vaccine creates immunity only in not affected by the virus women and against the virus, towards which it is pointed, i.e. the purpose of vaccination is to be done before the sexual activity.

The aim of the research is exploring the opinion of students and their parents about the use of a vaccine to prevent cervical cancer.

The subject of the research is the process of building a culture of health of young people and their subject position for participation in health prevention.

The objects of the survey are the attitudes, knowledge and assessment of different social groups for protection and preservation of their health and the health of others.

The sphere of the research are students from Medical Academy, Sofia, "Pharmacy" - 61, students from "St .St. Cyril and Methodius" school, Burgas - 30, students' parents - 50. The whole number of participants in the survey is 141. The research data is processed statistically and shown graphically with computer programme EXCEL.

Approaches and methods for the study of the problem: theoretical analysis of the problem in the medical literature; documentary research; anonymous questionnaire survey; comparative analysis. The results from the research are processed statistically and shown graphically with computer programme EXCEL.

\section{EXPOSURE}

In order to understand the state of the problem in practice, an anonymous survey in Medical Academy was done in January, 2016. 61 students from Pharmacy faculty participate in this survey. The age characteristic of the participating students is the following: the biggest group is that of 19-year-old students - 59\%, followed by the 20-year-old students - 29.5\%, 21-yearold are $8.2 \%$ and 18-year-old are presented by $3.3 \%$ (see fig. 1 ):

Fig. 1 Age characteristic of students

The facts from the survey show the students willingness to be vaccinated in order to protect themselves from HPV (Human Papilloma Virus). $49.2 \%$ of the students announce their decision not to be vaccinated, because according to them it is dangerous for their health. $13.1 \%$ say that they would not be vaccinated, because there isn't enough exploration for its benefit. For $8.2 \%$ the reason is "financial", the other $8.2 \%$ "aren't interested in the problem". Much lower is the percentage of these students who are ready to be vaccinated: $19.7 \%$ and of those who have already been vaccinated - only $1.6 \%$ (see fig. 2 ):

Fig. 2 Students' attitude towards vaccination

A recent study between 50 parents has been done about the opinion their daughters to be vaccinated, so that to be protected against infection with HPV. The age characteristic of parent can be introduced this way: the biggest group is that of 38year-old, the smallest is the group of 54year-old (see fig.3)

Fig. 3 Age characteristic of parents

$30 \%$ of parents, whose opinion has been studied, are with secondary education, $70 \%$ have university education. The source of information about the significance of the vaccination and the necessity of it for parents is media $-60 \%$ and for the others GP doctor $-18 \% .22 \%$ of parents "are not interested in this vaccine", because they think it is dangerous for health (see fig.4):

Fig. 4 Source of information about the necessity of vaccination 
The results from this study feature the unwillingness of one bigger part of parents to vaccinate their daughters - 54\%. From them $44 \%$ think that the vaccine is dangerous and $10 \%$ "no, because there are not clinically proved facts for its benefit. $30 \%$ agree to vaccinate their daughters, but "after some research". Only 16\% are convinced that it is useful (see fig.5):

Fig. 5 Parents' inclination for vaccination of their daughters

Knowledge and tendency have been surveyed among students at following age:

- 12-year- old students - $76.7 \%$

- 13-year-old students $-23.3 \%$

$83 \%$ of children confess that they have discussed the problem with their parents and have information from them, $10 \%$ are informed by a medical specialist at school, but $6.7 \%$ of children are ashamed to answer these questions. (see fig.6) The bigger part of children $-70 \%$ point, that they will consult with their parents, if they want to be vaccinated (see fig.7):

Fig. 6 Children's knowledge about the necessity of vaccination

Fig. 7 Children's attitude towards vaccination

In the process of this study a comparative analysis has been done, held in November 2012. A hundred of students from different subjects at "Prof. d-r A. Zlatarov" university, faculty of social sciences, Burgas participated. The results show that the students don't know well the ways of infection with HPV (Human Papilloma Virus). Although, during the last years the problem for the necessity of vaccination against this disease is widely discussed, in 2012 nearly $15 \%$ of students didn't know about the vaccines for prevention against HPV. The comparative analysis shows that in both years, 2012 and 2016, the participants in the survey share their fear and that's why they refrain: do vaccines cause any health complications, are there any side effects and what kind?

In $201271 \%$ of students say that they are not informed enough with vaccines and they need more information. Facts from the answers of $62 \%$ young people, studying in Burgas, featured their readiness to support their relative, sister or girlfriend to be vaccinated. Only 5\% aren't sure that "vaccine will solve the problem".

\section{CONCLUSION}

It's a human right everyone to determine the rules for his / her life, in this case - to be vaccinated or not. But when it concerns health, the rules are built on knowledge and formed attitude towards it as a value still in childhood, in the process of acquiring knowledge, information and skills.

One of the ways for improving personal health culture is creating conditions for realization of the process health education in all educating grades. [5] Knowing forms and methods of health education, organizing of thematic and informational days, concerning different health problems, help establishing proper attitude for health protection. The effect from final results in expression of preventing potential of health education aims bio-, psycho- and social health of personality. [6] The necessity of realization of the process health education prove these many questions, asked by students after they have filled in the survey card.

\section{LITERATURE}

[1] Margaritova, R , G. Terzieva. 2014 Mnenieto na studentite za vaksinirane sreshtu rak na matochnata shiika. Sb. Dokladi "Studentska nauchna sesia", Universitet "Prof. Asen Zlatarov", Burgas

[2] Meditsinski dnevnik, sp. str.7 http://spisaniemd.bg/md/2014/5/md 2014 5.p $\underline{\mathrm{df}}$

[3] Pod red. na Ivan Chernozemski, Todor Shishkov 2000 Onkologia 2001, S. 
[4] Pod red. na Ivan Chernozemski, prof Karanov 2009 Diagnostika, prosledyavane I lechenie na bolnite sas zlokachestveni novoobrazovaniya, $\mathrm{S}$.

[5] Terzieva, G 2013. Zdravno vazpitanie. Zdravna kultura. Mediko-sotsialni I pedagogicheski aspekti. Parvo izdanie. Izdat. Laks buk, Plovdiv

[6] Terzieva,G. Prevantivniyat potencial na zdravnoto obrazovanie Godishnik na universitet "Prof. d-r Asen Zlatarov", Burgas 2011, t. XL, s. $335-330$

[7] Ratsionalnaya farmakoterapiya $\mathrm{v}$ akusherstve I ginekologii , s. $682-686$ https://vk.com/doc21794509 302291895?hash $=74$ ea 3 ccca7629a09a $2 \& \mathrm{dl}=\mathrm{c} 0 \mathrm{~b} 1 \mathrm{e} 6 \mathrm{e} 7193 \mathrm{ff} 73$ $\underline{687}$

[8]Levin C, Sharma M, Olson Z, Verguet S, Shi IF, Wang SM, Qiao YL, Jamison DT, KimII. An Extended Cost-Effectiveness Analysis of Publicly inanced HPV Vaccination toPrevent Cervical Cancer in China.B: https://openknowledge.worldbank.org/bitstr eam/handle/10986/22552/9781464803499. pdf?sequence $=3$ \#page $=315$

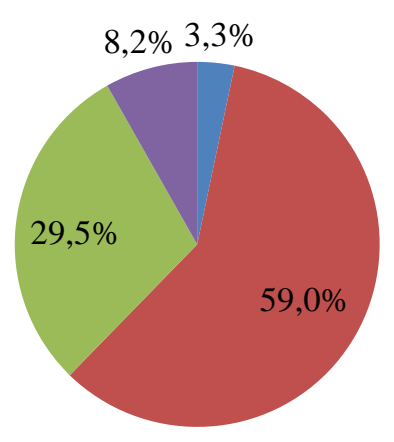

18-year-old

19-year-old

20-year-old

21-year old

Fig. 1 Age characteristic of students

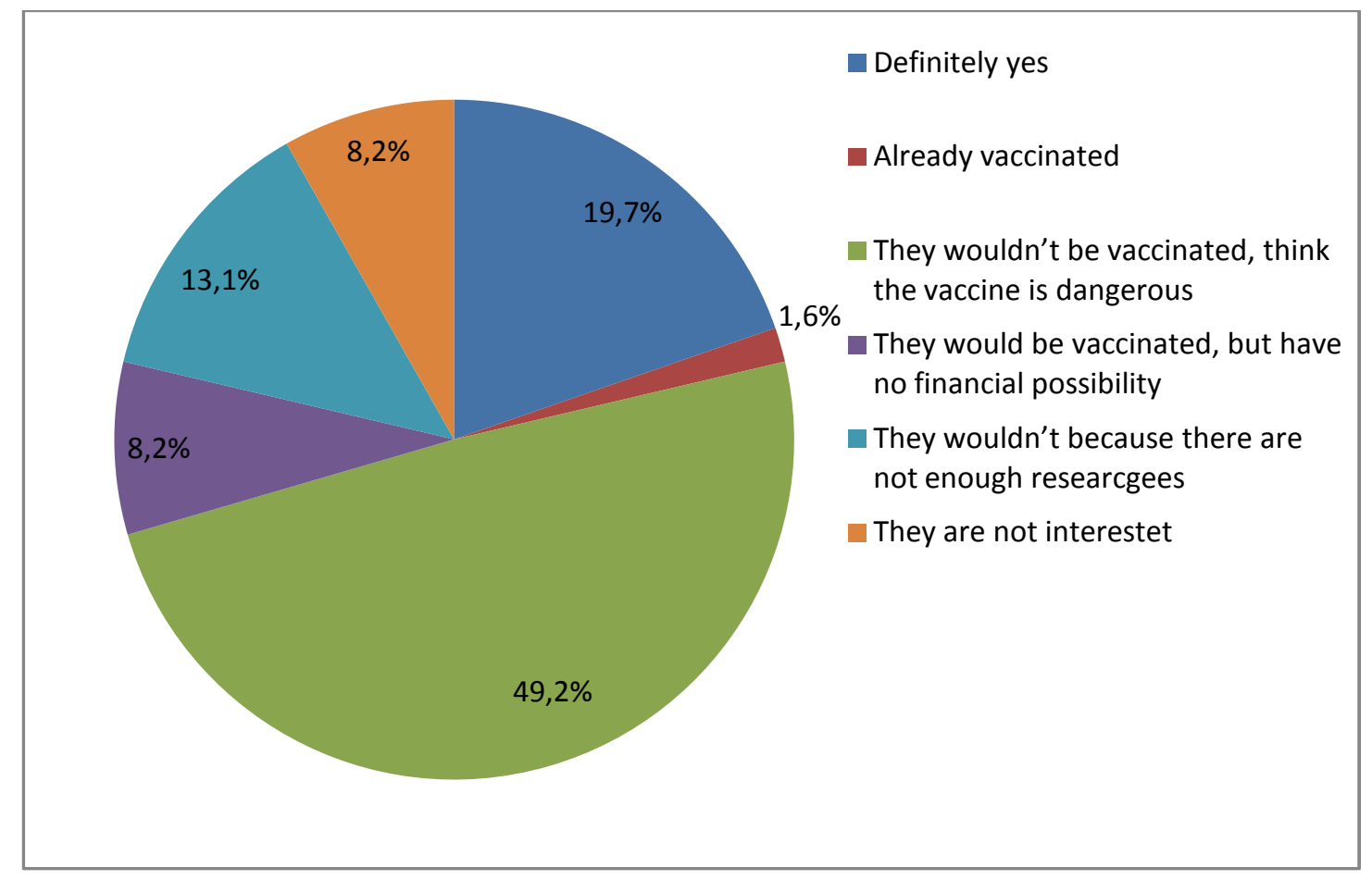

Fig. 2 Students' attitude towards vaccination 
(JPMNT) Journal of Process Management - New Technologies, International

Vol. 4, No.4, 2016.

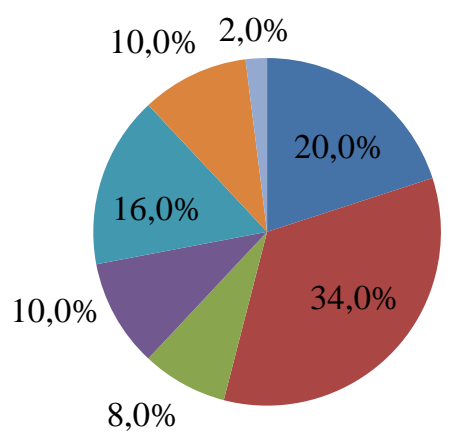

- 32-year old

- 38-year old

40-year old

- 41-year old

44-year old

45-year old

- 54-year old

Fig. 3Age characteristic of parents

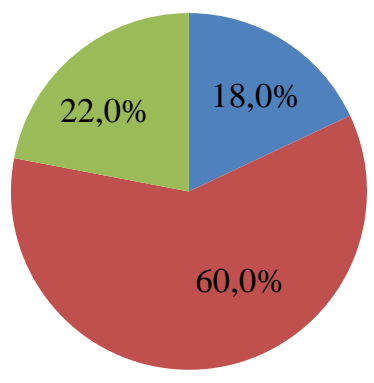

From my GP doctor

From media

I am not interested, I think the vaccine is dangerous

Fig. 4 Source of information about the necessity of vaccination

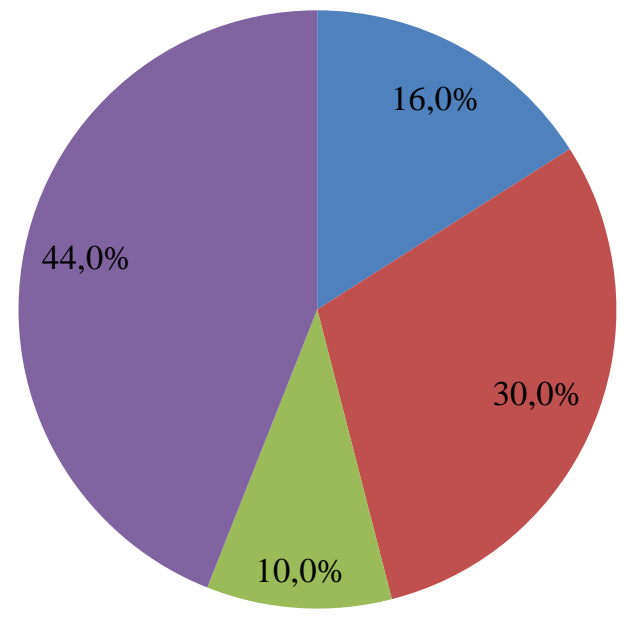

- Yes, I'm sure it helps

- Yes, but after some research

No, because there are not enough clinical facts about its usefulness

No, because I find it dangerous

Fig. 5 Parents' inclination for vaccination of their daughters 
(JPMNT) Journal of Process Management - New Technologies, International Vol. 4, No.4, 2016.

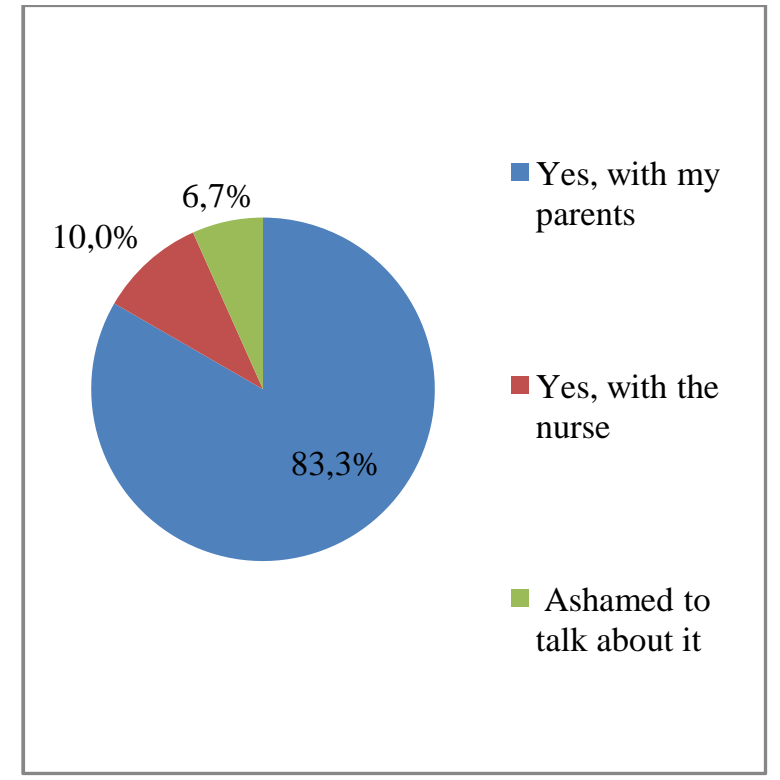

Fig. 6 Children's knowledge about the necessity of vaccination

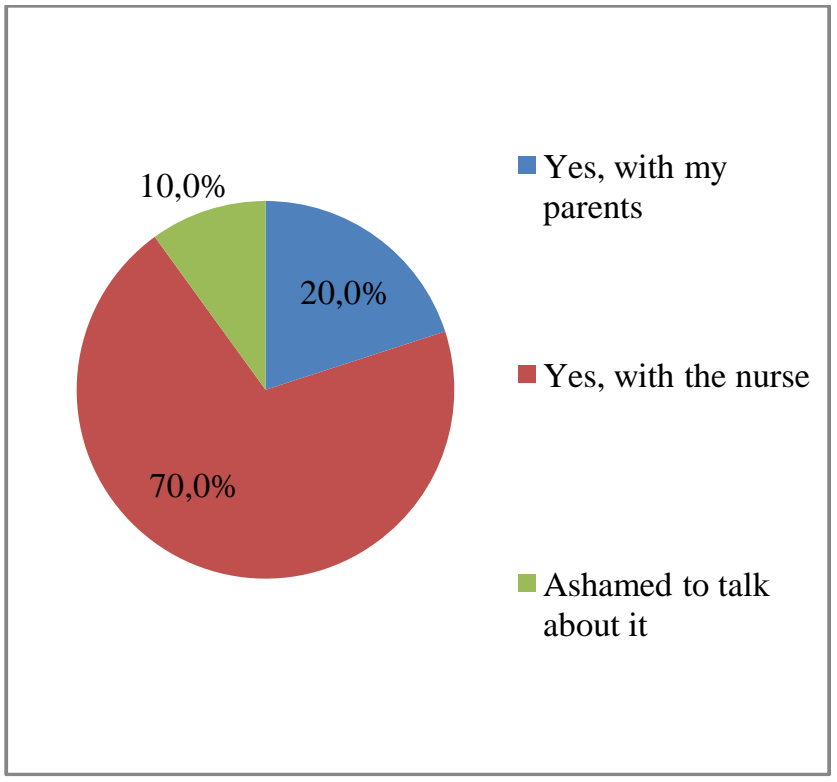

Fig. 7 Children's attitude towardsvaccination 